\title{
EL BUSTO DEL ARQUITECTO GARL GANGOLF KAISER
}

\author{
Michael Drewes
}

El archiduque Fernando Maximiliano de Habsburgo (1832-1867) era romántico y poco realista. No comprendió cómo el rey Fernando de Ambas Sicilias vivía después de la revolución de 1848 en la fortaleza de Gaeta, en cuartos muy ordinarios de una casa fea rodeada de bastiones, y pensó que sería muy propio que abdicara en vez de cambiarse del espléndido palacio de Caserta a tal lugar de residencia. ${ }^{1}$ Por tanto, tolera a un soberano con poderes reducidos y excluye a uno que carezca de un medio ambiente estéticamente atractivo. ${ }^{2}$ En el diario del egiptólogo austriaco Simón Leo Reinisch, quien fue comisionado por Maximiliano a México a fines de 1866 para proyectos de investigación acerca de las lenguas indígenas, ${ }^{3}$ encontramos la siguiente caracterización del monarca: ${ }^{4}$

Es siempre doloroso para mí oír hablar de hombres entendidos y cuerdos acerca del emperador Maximiliano, ya que me suministran cada vez datos nuevos que demuestran que este monarca, a quien por mucho tiempo tuve entre los Lorenenses por el más inteligente, tampoco sirve de nada. Posee de por sí algunos talentos, pero no ha aprendido nada en su vida y gozó de una mala educación. No quiere tener alrededor de sí cabezas que razonan claramente y caracteres abiertos, ya que teme que le adivinen sus intenciones, y es enemigo de puntos de vista claramente formulados aunque bien intencionados. Las personalidades de lacayo le son más bienvenidas. Preside apasionadamente sesiones de concejo, no para enterarse acerca de los temas por tratarse sino para mostrar sus 'ideas' siempre excelentes, según su punto de vista. iAy de quien manifieste una opinión contraria, por más bien fundada que sea! El emperador no la contradiría, incluso secundaría esta opinión ostentativamente, hasta le pediría al señor la ponga en papel y la presente como proposición elaborada -que con rapidez para en el cesto de basura del emperador, y el autor se verá

1 Joan Haslip, Imperial Adventurer, London, 1971, p. 43. Apud Maximilian von Mexiko (1832-1867) "Ausstellung auf Burg Hardegg, Wien, Verlag Enzenhofex, 1974, p 78.

${ }^{2}$ Klaus Eggert, "Kaiser Maximilian und seine Kunstschöpfungen", Maximilian von Mexiko, p. 72 .

${ }^{3}$ Johann Lukienski, Der maximilianeische Staat, Mexiko, 1861-1867, Böhlau Vexlag, WienKöln-Graz, 1988, pp 78-79

4 Ferdinand Anders, "Maximilian und Mexiko", Maximilian von Mexiko, pp 104-105. Anotación del 17 de febrero de 1867 en el diario de Reinisch, pocos días después de la salida del emperador a Querétaro. 
en la situación donde será relevado de la oportunidad de incomodar los oídos imperiales. Tengo mis experiencias al respecto - Su alma añora entretenimiento, placeres que tengan la apariencia de trabajo, preocupación por el bien del país y de los súbditos, es decir, quiere juguetear todo el santo día; en eternos jugueteos mata el tiempo. Ocasión no le falta; juguetea con los ministros, estando sentado con ellos día tras día, dictándoles modismos, escribiéndoles, además, cartas en las cuales explica sus 'ideas', pero qué y si de hecho lo hacen los ministros, por eso casi nunca se preocupó: -juguetea con su personal de gabinete que acerca de las frioleras principales tiene que elaborar todo un archivo de escritos: - para que esté en la posición de vociferar sus 'ideas propias y extrañas' acerca de esta o aquella cuestión científica que le es tan ajena como el hombre en la luna. Su trabajo es jugueteo, su voluntad, terquedad, su mando, absurdo y falso. - ¿Cómo sería posible que en este país creara paz y orden, para lo cual son indispensables conocimiento y discreción, trabajo arduo, perseverancia y energía? Los dos puntos de apoyo de su poder en México son un ejército bien organizado y un erario lleno; este último el emperador lo aniquiló en construcciones innecesarias y administración desordenada, y no se pensó sino hasta el tiempo de la salida de los franceses en la organización de una fuerza militar nacional apegada a él Sin embargo, las cosas están tan enmarañadas, de modo que hay poca esperanza de mantener el Imperio en México.

No sabemos si el arquitecto Kaiser, quien estuvo activo en México básicamente durante el año de 1866, a juzgar por sus diseños y escritos, ${ }^{5}$ haya corrido la misma suerte como tantos súbditos del emperador: que sus proposiciones en cuanto a mejorar la pésima administración de las obras públicas del Imperio hayan sido aplaudidas sólo aparentemente sin ser realmente tomadas en cuenta.

El concepto romántico que el emperador tenía de sí mismo, exigía la creación de ambientes exquisitos y lujosos, no importando los gastos que esto ocasionaba. Cabe mencionar que para el mantenimiento de los palacios de Miramar y Lacroma salieron 428000 pesos más 210000 pesos por cuenta de la emperatriz. ${ }^{6}$ Según un aforismo de Maximiliano, del 2 de junio de 1860, "la avaricia en los príncipes es un crimen, pues la masa siente siempre que su dinero sale de la bolsa de muchos. Los príncipes deben ser sólo máquinas de circulación del dinero, uno sabe agradecérselos."

\footnotetext{
${ }^{5}$ Michael Drewes, "Proyectos de remodelación del palacio de Chapultepec en la época del emperador Maximiliano", Anales del Instituto de Investigaciones Estéticas, vol XIII, núm. 51 (1983), pp. 73-82, y "Carl Gangolf Kaiser (1837-1895), arquitecto de la corte del emperador Maximiliano", idem, 59 (1988), pp. 239-254.

${ }^{6}$ Ferdinand Anders, Die Gärten Maximilians, Wien, 1987, p. 28

${ }^{7}$ Erzherzog Ferdinand Maximilian, Aus meinmen Leben, tomo VII, Leipzig, 1867; apud Maximilian von Mexiko, p. 168
} 
El archiduque quería realizar proyectos ambiciosos y fastuosos de obras públicas en México, para lo cual Carl Gangolf Kaiser recibió finalmente la comisión de supervisar y dirigirlos, al haber sido nombrado arquitecto de la Corte.

Generalmente no es muy común toparse con la efigie de un artista, ya que no todos legan su autorretrato a la posteridad. Sin embargo, en el caso de nuestro arquitecto nos encontramos ante la circunstancia feliz de dar a conocer su "vera imagen". 8

Kaiser nace el 12 de febrero de 1837 en Viena, estudia arquitectura en su ciudad natal y luego con Ludwig Lange (1808-1868) en Munich. Después de viajes en Europa, Norte y Centroamérica trabaja, de 1864 a 1867, en proyectos de remodelación del Palacio Nacional y del Castillo de Chapultepec en la ciudad de México, y de la casa de Cortés en Cuernavaca. ${ }^{9} \mathrm{El}$ emperador lo nombra miembro de una comisión para supervisar la implementación de un museo en el palacio de Miramar, ${ }^{10} \mathrm{y}$ después del desenlace trágico del Imperio se dedica a la restauración y modernización de castillos y palacios austriacos, como el de Hardegg, sede del actual museo de Maximiliano, realizado en colaboración con Humbert Walcher, caballero de Moltheim de 1878 a $1893 .{ }^{11} \mathrm{El} 12$ de septiembre de 1895 muere en el manicomio de Inzersdorf cerca de Viena, destino que comparte con su compatriota, el pintor Josef Selleny (1824-1875), quien acompañó al archiduque en su viaje de circunnavegación de la fragata "Novara" de 1857 a 1859.12

El escultor Víctor Oskar Tilgner hizo un busto-retrato del arquiteto Kaiser en mármol proecedente de Salzburgo, que representa al alarife en un atuendo medieval, conforme a la tendencia historicista de la época, y en

\footnotetext{
${ }^{8}$ Agradezco al Sr. Wilfried Enzenhofer, secretario de la asociación del Castillo y del Museo de Hardegg que administra el archivo de Maximiliano, el haber enviado una reproducción de la fotografía contemporánea, tomado por J. Löwy, del busto de Carl Gangolf Kaiser:

${ }^{9}$ Ulrich Thieme, y Felix Becker, Allgemeines Lexikon der bilden-Künstler von der Antike bis zur Gegenwart. Verlag von E A Seeman, tomo xx, Leipzig, 1927, p. 45. Aquí se consigna el hecho de que Kaiser estudiara con el pintor paisajista Julius Lange (1817-1878), y no con su hermano Ludwig, el arquitecto quien llegó a ser profesor de la Academia en 1847, y cuyo primer período de creatividad se caracteriza por edificios románico-bizantinos, mientras que en el segundo revive formas renacentistas. Idem, tomo XXII (1928), pp. 327-328. En Eckart Vancsa, "Zu Carl Gangolf Kayser, ein Wiener Architekt des Späthistorismus", ARX, Burgen und Schlösser in Bayern, Oesterreich und Südtirol, núms. 3-4. Wien-St. Michael/Eppan-München, 1980. p. 17, se contempla la posibilidad de un error al mencionarse a Julius Lange como maestro de Kaiser Además, en este artículo se analizan las obras austriacas de él.

${ }^{10}$ Werner Kitlitschka, "Erzherzog Ferdinand Maximilian und die bildende Kunst", Maxi milian von Mexiko, p. 63.

${ }^{11}$ Carta del Sr. Wilfried Enzenhofer, del 16 de marzo de 1989

${ }^{12}$ Maximilian von Mexiko, p. 183, y Thieme-Becker, op cit., tomo XXX, p. 479.
} 
la base reza la inscripción, en caracteres góticos: "Karl Gangolf Kayser." 13 Me inclino a creer que la escultura fue hecha después del regreso de Kaiser a Austria, ya que la fisonomía es la de un hombre maduro, y el arquitecto era bastante joven cuando acompañaba al archiduque en su fallida expedición a México.

El busto se encuentra actualmente en el castillo de Kreuzenstein -que Kaiser restauró-, cerca de Korneuburg en la Baja Austria, en posesión privada de los condes de Wilczek, ${ }^{14}$ para quienes el arquitecto modernizó el castillo de Seeborn. En Hardegg se exhibe una fotografía de la escultura, ${ }^{15}$ y en el Museo Histórico de la Ciudad de Viena se halla una copia en yeso.

De Tilgner consignamos los siguientes datos biográficos: ${ }^{16}$ nace el 25 de octubre de 1844 en Presburgo (Poszony) en Hungría, hoy Eslovaquia, y muere el 16 de abril en Viena. Alumno de la Academia de las Artes Plásticas de 1859 a 1871, recibe en 1865 la medalla Füger, y en 1869 , una beca. El escultor francés Gustave Deloye, residente en Viena de 1872 a 1873, lo motiva a seguir el barroco, y Tilgner se hace famoso con el busto de la actriz trágica Charlotte Wolter, que por su perfección técnica y su virtuosismo barroquizante le vale una medalla de oro en la exposición mundial de Viena en 1873. En 1874 efectúa un viaje de estudios a Italia con su amigo, el pintor Hans Makart (1840-1884).

Su talento se desparrama en innumerables bustos-retrato de yeso policromado y laqueado en imitación de mayólica, del famoso poeta austriaco Franz Grillparzer (1791-1872) y de Hans Makart y otros personajes, además de bustos integrados en monumentos, como aquellos de los compositores Anton Bruckner (1824-1896) en el parque municipal de Viena, Johann Nepomuk Hummel (1778-1837) en Presburgo, y de Franz Liszt (1818-1886) en Oedenburg (Sopron), Hungría.

Tilgner goza de un talento amable, de creatividad fácil, manifiesto en sus incontables fuentes, estatuas y esculturas funcrarias "Sus dos obras mayores, el monumento brutalmente realista del rey de las armas Josef Wernal en Steyr, y aquel dedicado a Mozart, erigido en 1876 en Viena, son

\footnotetext{
${ }^{13}$ Sobre la ortografia de nombres y apellido del arquitecto hay discordancias. Personalmente prefiero la grafia "Kaiser", apoyándome en las furmas en los planos de la Colección Orozco y Berra en el Observatorio de Tacubaya

${ }^{14}$ Carta del Sr. Wilfried Enzenhofer, del 13 de abril de 1989

15 Número de inventario 444, Maximilian von Mexiko, p. 250. Tilgner hizo también un pequeño busto en yeso, del geólogo Ferdinand Hochstetter (1829-1884), quien acompañó al archiduque Fernando Maximiliano en su viaje de circunnavegación, de 1857 a 1859, en la fragata "Novara". Número de inventario 55, idem, p. 185.

16 Thieme-Becker, op cit., tomo XXXIII (1939), p. 169
} 
DOI: http://dx.doi.org/10.22201/iie.18703062e.1992.63.1637

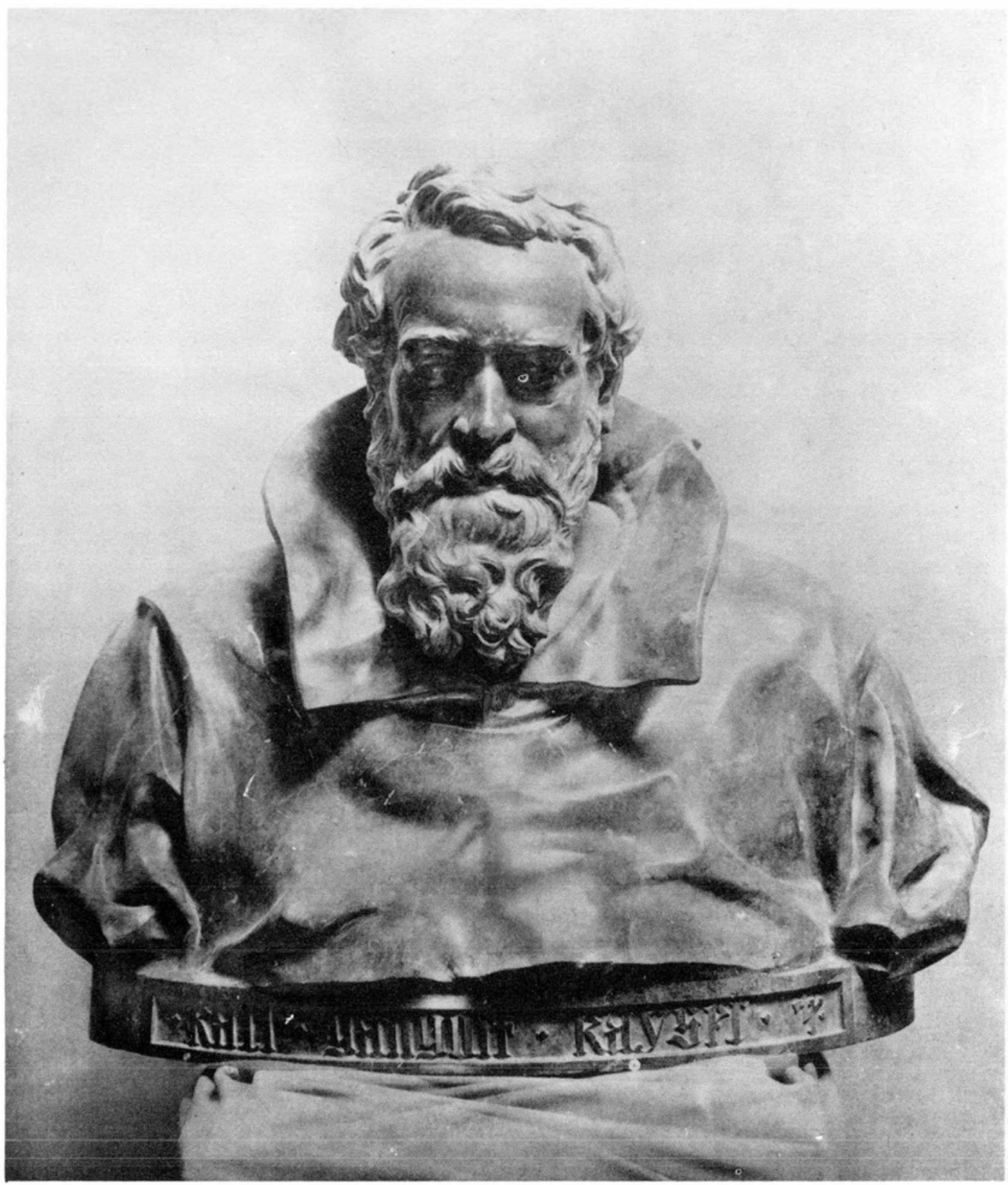

1. Gangolph Kaiser. 

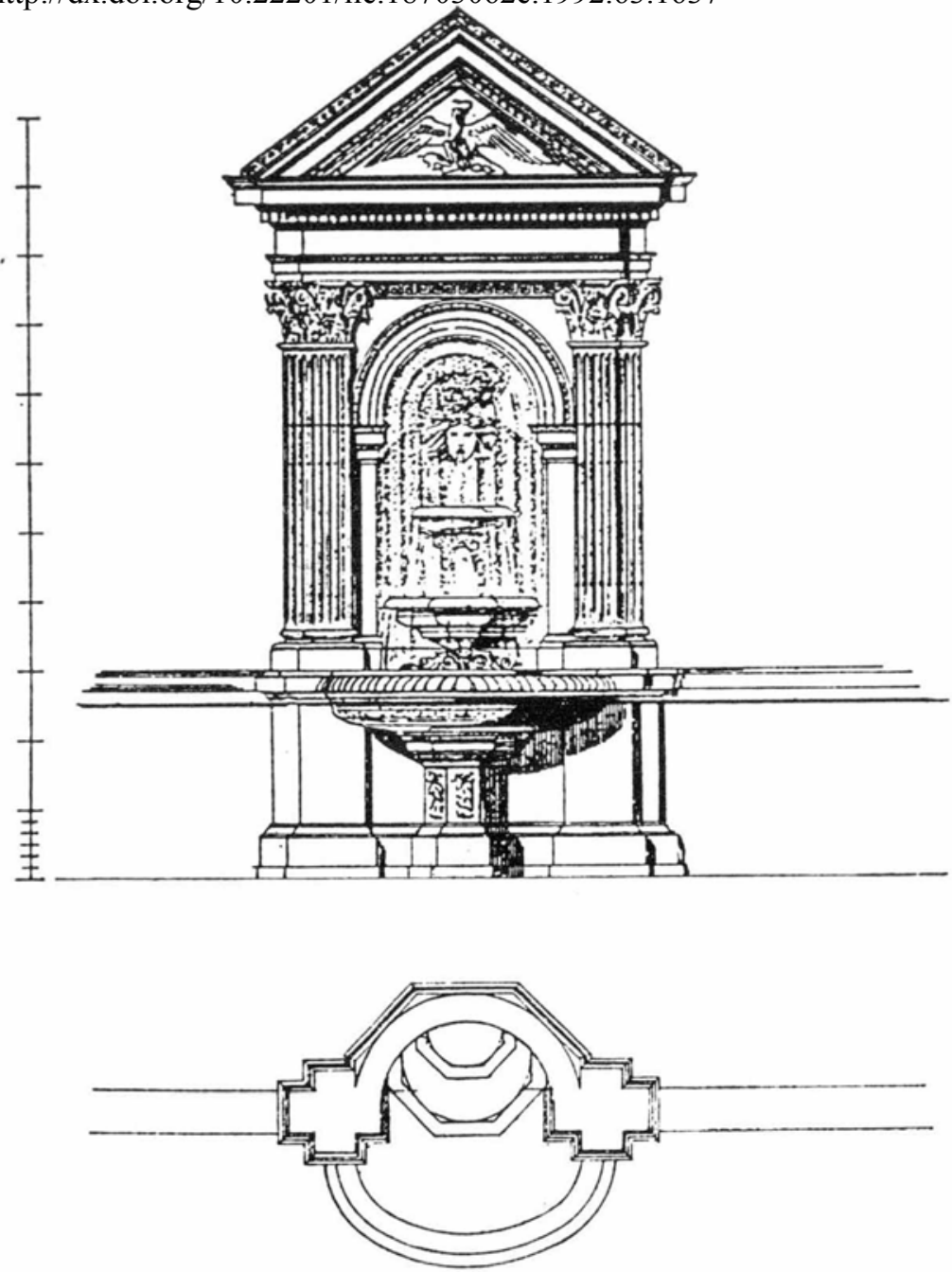

2. C. Kaiser. Fuente exenta. Col. Orozco y Berra, legajo 1564.

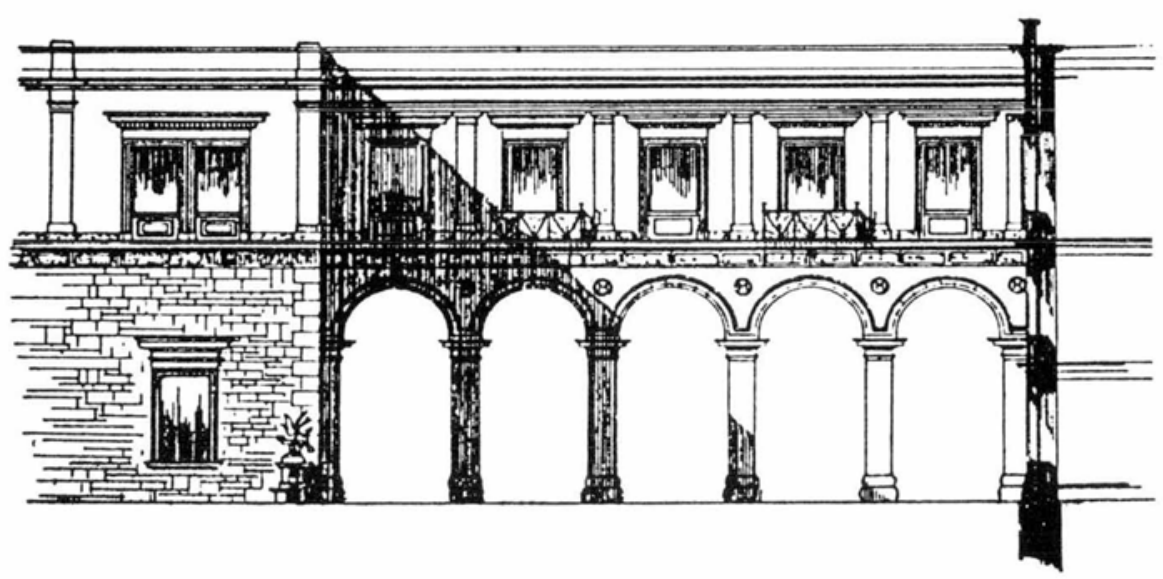

3. C. Kaiser. Puenteos. Colección Orozco y Berra, legajo 1564. 
creaciones artesanales por incluirse más bien entre las llamadas artes menores, transformadas en una escala gigantesca. Sus estatuas decorativas, bustos de artistas y poetas pueblan varios edificios de la Viena de los años setenta y ochenta del siglo pasado. Un retrato del escultor, del pintor Hans Temple, se exhibe en el Museo Histórico de la Ciudad de Viena.

Finalmente, presentamos dos planos del arquitecto Kaiser: uno, de una fuente exenta, y otro, de unos "puenteos" -lo que quiere decir el título en alemán-, para ligar dos edificios contiguos mediante un pasaje elevado. Ambos son diseños para el alcázar de Chapultepe ${ }^{17}$ y muestran el estilo de dibujo refinado y fluido de su autor, por cierto, idéntico a aquel de su colega Julius Hofmann, quien en 1866 proyectara la casa de campo de Maximiliano, "El Olindo", en Apacingo, cerca de Cuernavaca. ${ }^{18}$ Los planos de Hofmann para palacio y jardines de Lacroma, cerca de Ragusa en la costa del mar Adriático, denotan la semejanza de estilo con los dibujos de Kaiser ${ }^{19}$

Hemos logrado poco a poco reconstruir la personalidad del arquitecto de la corte de Maximiliano, del cual ninguno de sus proyectos mexicanos logró realizarse, ya que el tiempo era demasiado corto, y su actividad cayó en un verdadero momento de crisis al empezar a declinar el Imperio a partir de principios del año de 1866.

${ }^{17}$ Colección Orozco y Berra, legajo 1564.

${ }_{18}^{18}$ Anders, op. cit., p. 24 (Véase nota 6).

${ }^{19}$ Idem, p 23, e ilustración en Maximilian von Mexiko. Los originales se hallan en la colección gráfica de la Albertina de Viena, número de catálogo 148. 